\title{
SAGES Reimagining Education \& Learning (REAL) project
}

\author{
Jonathan Dort $^{1}$ (1) $\cdot$ John Paige $^{2} \cdot$ Alia Qureshi $^{3} \cdot$ Erin Schwarz ${ }^{4} \cdot$ Shawn Tsuda $^{5}$ \\ Received: 15 December 2021 / Accepted: 3 January 2022 / Published online: 31 January 2022 \\ (c) The Author(s), under exclusive licence to Springer Science+Business Media, LLC, part of Springer Nature 2022
}

\begin{abstract}
Background The COVID-19 pandemic has presented multiple challenges for health systems throughout the world. The clinical priorities of redirecting personnel and resources to provide the necessary beds, care, and staff to handle the initial waves of infected individuals, and the drive to develop an effective vaccine, were the most visible and rightly took precedent. However, the spread of the COVID-19 virus also led to less apparent but equally challenging impediments for healthcare professionals. Continuing professional development (CPD) for physicians and surgeons practically ceased as national societies postponed or canceled annual meetings and activities. The traditional in-person conferences were no longer viable options during a pandemic in which social distancing and minimization of contacts was the emerging norm. Like other organizations, The Society of American Gastrointestinal and Endoscopic Surgeons (SAGES) had to first postpone and then cancel altogether the in-person 2020 Annual Meeting due to the contingencies brought about by the COVID-19 pandemic. As a result, the traditional hands-on (HO) courses that typically occur as part of the Annual Meeting, could not take place. SAGES had already begun to re-structure these courses in an effort to increase their effectiveness (Dort, Trickey, Paige, Schwarz, Dunkin in Surg Endosc 33(9):3062-3068, 2019; Dort et al. in Surg Endosc 32(11):4491-4497, 2018; Dort, Trickey, Schwarz, Paige in Surg Endosc 33(9):3062-3068, 2019). The cancelations brought about by COVID-19 provided an opportunity to refine and to innovate further.

Methods In this manner, the Re-imaging Education \& Learning (REAL) project crystallized, an innovative effort to leverage the latest educational concepts as well as communication and simulation-based technologies to enhance procedural adoption by converting $\mathrm{HO}$ courses to a virtual format.

Results and conclusion This manuscript describes the key components of REAL, reviewing the restructuring of the HO courses before and after the spread of COVID-19, describing the educational framework underlying it, discussing currently available technologies and materials, and evaluating the advantages of such a format.
\end{abstract}

Keywords Education $\cdot$ COVID-19 $\cdot$ Educational framework $\cdot$ Hands-on courses

The COVID-19 pandemic has presented multiple challenges for health systems throughout the world. As it spread across the world, it initially threatened to overwhelm hospital capacities, forcing suspension of most non-emergent clinical services. Consequently, a redirection of personnel and

\footnotetext{
Jonathan Dort

Jonathan.dort@inova.org

Inova Fairfax Medical Campus, Falls Church, VA, USA

2 Louisiana State University Health Sciences Center, New Orleans, LA, USA

3 Oregon Health and Science University, Portland, OR, USA

4 SAGES, Los Angeles, CA, USA

5 Valley Health System, Las Vegas, NV, USA
}

resources occurred in which every effort focused on providing the beds, care, and staff necessary to handle the initial waves of infected individuals. In the USA, these regional and local efforts combined with federal policies to ensure that adequate equipment and therapies were available to treat the critically ill. Finally, an unprecedented drive to rapidly develop an effective vaccine began.

Although such clinical priorities were the most visible and rightly took precedent, the spread of the COVID-19 virus also led to less apparent but equally challenging impediments for healthcare professionals. Continuing professional development (CPD) for physicians and surgeons practically ceased as national societies postponed or canceled annual meetings and activities. The traditional inperson conferences were no longer viable options during a 
pandemic in which social distancing and minimization of contacts was the emerging norm. Societal leaders faced a new reality that required novel and innovative approaches to education and learning.

Like other organizations, The Society of American Gastrointestinal and Endoscopic Surgeons (SAGES) had to first postpone and then cancel altogether the in-person 2020 Annual Meeting due to the contingencies brought about by the COVID-19 pandemic. As a result, the traditional hands-on (HO) courses that typically occur as part of the Annual Meeting, could not take place. SAGES had already begun to re-structure these courses in an effort to increase their effectiveness [1-3].The cancelations brought about by COVID-19 provided an opportunity to refine and to innovate further. In this manner, the Re-imaging Education \& Learning (REAL) project crystallized, an innovative effort to leverage the latest educational concepts as well as communication and simulation-based technologies to enhance procedural adoption by converting $\mathrm{HO}$ courses to a virtual format. This manuscript describes the key components of REAL, reviewing the restructuring of the HO courses before and after the spread of COVID-19, describing the educational framework underlying it, discussing currently available technologies and materials, and evaluating the advantages of such a format.

\section{Transforming hands-on courses before and after COVID-19}

Face-to-face HO courses have long served as the traditional educational paradigm for teaching new skills and techniques to practicing surgeons [4]. These courses are typically offered either as a half-day or day-long experience at large regional or national meetings during which participants practice new skills or techniques on cadaveric or porcine specimens. Although this simulation-based training (SBT) helps clinicians acquire critical skills and competencies [5], subsequent adoption of a targeted procedure or technique by a clinician is rare as a result of these one-time, mass training events [6, 7]. Furthermore, faculty development of course instructors is lacking [8], and standards do not exist related to curricula, training models, or training facilities [9]. Consequently, low rates of adoption of the learned procedures and low confidence while performing the specific procedure are common outcomes for attendees $[4,5]$. When these new techniques are not meaningfully incorporated into a surgeon's practice, the low adoption rate represents a poor return on investment of the time spent by the faculty and learners, and the financial investment by the society and commercial supporters, if any.

\section{Development of the Acquisition of Data and Outcomes for Procedure Transfer (ADOPT) program}

In an effort to address the low adoption rate of procedures and techniques by participants of traditional $\mathrm{HO}$ courses at the Annual Meeting, SAGES developed the Acquisition of Data and Outcomes for Procedure Transfer (ADOPT) program. ADOPT optimizes the transfer to practice of new procedures and techniques taught at SAGES HO courses with two innovations. First, the faculty-learner interaction is standardized through faculty development and structured teaching. Second, faculty instructors and course participants engage in a longitudinal mentorship over the course of the subsequent year to assist with overcoming any challenges and obstacles to implementation of the learned techniques.

Starting in 2015, SAGES began offering this innovative, prospective program with a pilot course [1]. Over subsequent years, ADOPT has expanded and evolved. During this period, the following ADOPT HO courses have taken place during the SAGES Annual Meetings:

\section{5-2016: Pilot ADOPT Hernia Program [1] \\ 2016-2017: ADOPT Hernia Program [2] \\ 2017-2018: ADOPT Lap Colon Program [3] \\ 2018-2019: ADOPT Lap Colon Program \\ 2019-2020: ADOPT Colon Intracorporeal Anasto- \\ mosis and ADOPT Paraesophageal Hernia Programs}

After the initial HO course, longitudinal educational activities continue throughout the year to increase learners' adoption of learned techniques into surgical practice. Learners receive coaching, instruction, and advice. They develop mentor-mentee relationships, attend webinar courses, complete follow up surveys, participate in a private Facebook group, watch online videos, and interact with the faculty [1-3]. Each year, the needs assessment completed by attendees from the prior year's Annual Meeting serves to identify the next topic for an ADOPT course [1-3]. In this manner, the surgical techniques and procedures represent the most desired skills and procedures as expressed by SAGES members.

All participants work with mentors for an entire year following the course. This longitudinal experience abandons the one-off session in favor of continuous availability enhanced by structured interactive instructional events in the form of the webinars, and teleconferences [1-3]. In fact, prior to the COVID-19 pandemic, the day-long HO course served as the only session given in person. The remainder of the educational activities employed a virtual format via webinars, phone conferences, and Facebook interactions.

The standardization of the teaching method employed at the $\mathrm{HO}$ course improves the interaction between faculty 
and learners [10]. All faculty/mentors participate in a train-the-trainers course based on the Laparoscopic Colectomy (Lapco) Train the Trainer (TT) program developed in the United Kingdom [11]. The techniques taught in this two-day session standardize the teaching/mentoring given to all course participants. Only mentors who complete this course are permitted to act as faculty for an ADOPT program. This teaching utilizes evidence-based best practices to optimize learning. A Set-Dialogue-Closure structure governs the HO interaction in which faculty and learner first set goals and align agendas, proceed to undergo structured dialogue during teaching, and finish with a debrief concluding with a take home message [10].

ADOPT courses have consistently shown increased adoption of procedures and techniques taught at SAGES HO courses as well as increased confidence and comfort levels in performing them [1-3]. Part of the success of this program lies in the fact that multiple exposures and longer durations continuing medical education (CME) optimizes educational outcomes $[4,5]$.

\section{The COVID-19 pandemic and challenges to surgical education and CPD}

The impact of COVID-19 on surgical education was substantial. Time and space for residency and medical school education has become limited, forcing adaptation. For example, surgical training programs implemented virtual interviews for the incoming surgical trainees [12]. Given the rapidly evolving issues and timelines necessitated by the spread of the virus, little opportunity existed to create and implement alternative educational platforms, although institutions across North America have scrambled to do so [13]. To fill the void, surgeons and surgical trainees have turned to existing virtual platforms such as Websurg ${ }^{\mathrm{TM}}$ and Incision Academy ${ }^{\mathrm{TM}}$, offering interactive video and teaching modules for surgical learning [13]. The efforts remained disjointed and disparate, however, especially when surgeons were focusing more on prioritizing care for patients who required a delay in care during the initial wave of the pandemic [14]. Recommendations have included using videobased operative education, virtual lectures, podcasts, social media, virtual simulation, and tailored content incorporating design best practices and lasting only 15 to $20 \mathrm{~min}$.[15]

CPD has suffered from the spread of COVID-19 across the globe. Due to the pandemic, the trillion-dollar worldwide conference industry took a major hit [16]. In the field of medicine, massive cancelations occurred after evidence of spread from a meeting of staff from the biotech company Biogen in early March [17]. The SAGES Annual Meeting scheduled for April 2020 was one such casualty. In order to continue with the ADOPT program planned for the 2020 Annual Meeting, an innovative, novel approach was necessary. Through the ADOPT changes prior to the pandemic, SAGES had already standardized the educational instruction given during the HO portion of the course. REAL and the impact of COVID-19 helped push SAGES to conceptualize standardizing the educational delivery, since the educational framework, technology, and training models existed to create a self-contained learning and assessment tool for technical skills.

\section{The educational framework for REAL}

Although COVID-19 prevented the large group, face-to-face interaction of a traditional SAGES HO course, an alternative teaching structure using sound, avant-garde educational principles and techniques does exist. In other words, in education science, the concepts needed to re-structure HO courses are already available. Three of these concepts are especially useful in the current context: (1) the flipped classroom, (2) longitudinal mentorship, and (3) community of practice.

\section{The flipped classroom}

A flipped classroom, also known as a reverse classroom, gets its moniker from the fact that the flipped educational format serves as mirror image of the traditional format. It consists of "school work at home and home work at school." [18] Thus, instead of a teacher presenting a lecture in class to learners who then do assigned problem solving away from the classroom, pupils receive assignments to learn foundational concepts before class, devoting actual class time with the teacher to active learning via meaningful interactions that cognitively engage the learners $[19,20]$. Such a format has many advantages. They include increased opportunities for individualized education, increased teacher-learner interaction time, improved learner self-direction, increased likelihood of pupils taking responsibility for their own education, and increased student flexibility in learning [21].

The Flipped Learning Network [18] delineates four key characteristics crucial to the success of a reverse classroom. The first characteristic is a flexible learning environment. In a flipped classroom, the learning space is fluid, allowing for the creation of environments tailored to the content. In addition, timelines and assessments are more flexible, based on student learning. The second characteristic is a learning culture emphasizing a learner-centered approach. The emphasis thus is on knowledge construction by the pupil who evaluates learning in a more personal, meaningful manner. The third characteristic is the use of intentional educational content to maximize class time by using active learning, pupilcentered strategies to develop conceptual understanding, and procedural fluency. The fourth characteristic is the use of 
professional educators whose roles are manifold. They must constantly observe and assess learners, providing timely feedback during class time. They also must continually evaluate and improve teaching techniques and modalities in order to maximize the effectiveness of the learning activities.

The flipped classroom format has begun to gain more traction in health sciences education. Several systematic reviews have demonstrated its significant superiority overall [22] and with specific academic outcomes [23] compared to traditional classroom formats. Other meta-analyses, however, have not shown such a benefit $[19,20]$. Such reviews do report positive student perceptions of the flipped classroom format [20, 22]. Importantly, Chiu et al. [24] have successfully employed the flipped classroom structure to teach laparoscopic surgical skills. They showed that medical students randomly assigned to a flipped classroom performed significantly better in several intracorporeal knot-tying skills compared to students learning in a traditional classroom setting.

Jones-Bonofiglio et al. [25] successfully created an online CPD course using a flipped classroom format to teach faculty simulation-based research. Learners identified the need for psychological safety, adequate time, and regular interaction as important to the overall effectiveness of a flipped classroom online. They enjoyed the format, particularly its learner-centered and problem-centered focus. Finally, they felt that it helped them achieve their own particular learning objectives in addition to the stated course learning objectives.

Moffett [21] has identified twelve items to keep in mind when implementing the flipped classroom format. One should employ established educational principles and evidenced-based techniques. One should capitalize on the positive features of the format and decide how to organize the material. One should choose pre-class materials carefully and utilize virtual learning environments. One should use class time creatively and effectively and tailor material to students' needs. One should be aware of the time and effort needed to convert to a flipped format and should provide the necessary faculty development. One needs to prepare students and determine the appropriate method of assessment. Finally, one should not feel that creating a flipped classroom is a binary proposition. In other words, a course need not be only flipped or traditional in format.

\section{Longitudinal mentorship}

The concept of mentorship can trace its origins to Homer's Odyssey in which the goddess Athena disguises herself as Odysseus's old friend Mentor to provide guidance and direction to his son Telemachus [26]. In health professional's education, it serves as a way to guide inexperienced initiates in the intricacies of an often complex healthcare system [27]. Key characteristics of the mentorship relationship include dynamism, mutual beneficence, contextual specificity, goal orientation, and developmental focus [28]. In this relationship, both mentor and mentee have specific roles and expectations that, if followed, will help lead to the success of the mentorship [27].

Chopra et al. [29] divide mentorship into four main representations. The traditional mentorship model has the mentor devoting considerable time in counseling a mentee on career decisions, projects, and the like. Such traditional interaction is longitudinal in nature. In the coach model, the "mentor" helps the mentee focus on improvement in performance on a specific issue or skill. In the sponsor model, the "mentor" risks reputation to promote a promising mentee, expecting the mentee to be successful in the undertaking. In this form of mentorship, the mentee might not even know the individual. Finally, the connector model of mentorship involves "mentors" using their large networks of connections to match mentees to traditional mentors, coaches, and sponsors.

Krishna et al. [28] view mentorship as a continuum incorporating aspects of role modeling, teaching and tutoring, coaching, and supervising. This continuum also involves components of learner motivation, the learning relationship, the learning environment, and, finally, learning assessment. The authors emphasize the role of coaching in the mentor-mentee relationship. This emphasis is important, since surgical coaching has multiple benefits. It can teach non-technical skills, improve technical skills as well as intra-operative decision-making, and potentially support surgeons in low- and middle-income countries in learning new procedures [30].

Mentorship in surgery can exert a powerful influence, preventing behavioral change [31]. Ethical issues also can have negative impacts on the mentorship relationship including lapses in conduct, incorrect understandings of roles and responsibilities, poor alignment of expectations, and lack of clarity regarding standards of practice [32]. On the other hand, surgical mentoring can positively influence surgical outcomes. For example, Miskovic et al. [33] demonstrated that mentoring in laparoscopic colectomy resulted in statistically lower conversion rates compared to no mentoring. In addition, surgeons who had mentors had rates of conversion, anastomotic leak, and mortality similar to experts.

Finally, mentorship is adaptable to online and web-based applications. Jaffer et al. [34] found that World Wide Web (www) 2.0 and 3.0 technology offered interesting possibilities for medical mentoring, including greater interaction, search capabilities, and, for 3.0 technology, immersive environments. In addition, surgical telementoring has gained in popularity. Recently, Erridge et al. [35] found that it had similar safety and efficacy profiles as on-site mentoring. 


\section{Community of practice}

First coined by Lave and Wenger to describe the work community acting as a living curriculum for apprentices within a particular trade, the definition of a community of practice has evolved to encompass three key characteristics. First, it has a shared domain of interest, implying a shared competence distinguishing the members from other individuals. Second, it forms a community that engages, interacts, and learns together, building relationships. Third, it creates a shared practice or repertoire of experiences, stories, tools, or ways of addressing problems. A useful definition incorporating these essential components follows: "Communities of practice are groups of people who share a concern or a passion for something they do and learn how to do it better as they interact regularly." [36]

Within the community of practice framework, learning arises from the cultural practices of the community. Thus, it is not dependent on knowledge derived from books, lectures or other explicit forms, but, instead, it situates itself within the context of work itself, arising from problem solving challenges and social processes surrounding an actual problem. In other words, a community of practice emphasizes knowledge-as-situated more so than knowledge-in-thehead. Doing so requires placing learning within an authentic cultural environment [37].

Within a community of practice, experts and novices can interact. Experts often comprise the core interactions with the novices on the periphery. Through legitimate peripheral learning, these novices can begin to interact and move from the periphery to the core of the community as they gain expertise and experience. This progression allows other novices to join and begin to learn at the periphery [38].
Surgery has multiple potential communities of practice within which a surgeon can participate. Examples include an operating room community of practice made up of interprofessional clinicians as well as a community of practice of minimally invasive foregut surgeons. Quinn et al. [39] have demonstrated that a surgical journal club meets the domain, community, and practice criteria of a community of practice. Additionally, virtual communities of practice in health care and surgery are possible with the literature citing examples on social media [40], LinkedIn [41], and online [42].

\section{Applying educational concepts to re-structure hands-on courses}

Figure 1 illustrates how the concepts of flipped classroom, longitudinal mentorship, and community of practice have helped re-structure traditional $\mathrm{HO}$ courses to enhance their effectiveness and extend their reach. Using the flipped classroom format, enrollees can have online, web-based pre-course assignments given to them. Such assignments might include video review of procedures or lectures on salient topics, links to web-based articles or sites related to the subject, or a knowledge-based pre-course assessment to gain a better understanding of an enrollee's starting point. The HO course itself then becomes a small group, highly interactive faculty-learner experience focusing on the learner's desired objectives and involving immediate feedback from the faculty.

The course then transitions into a longitudinal mentorship model. Enrollees meet their assigned mentor prior to the course, who would be their faculty member. This precourse interaction helps set goals for the experience. In addition, it would help build the mentor-mentee relationship.
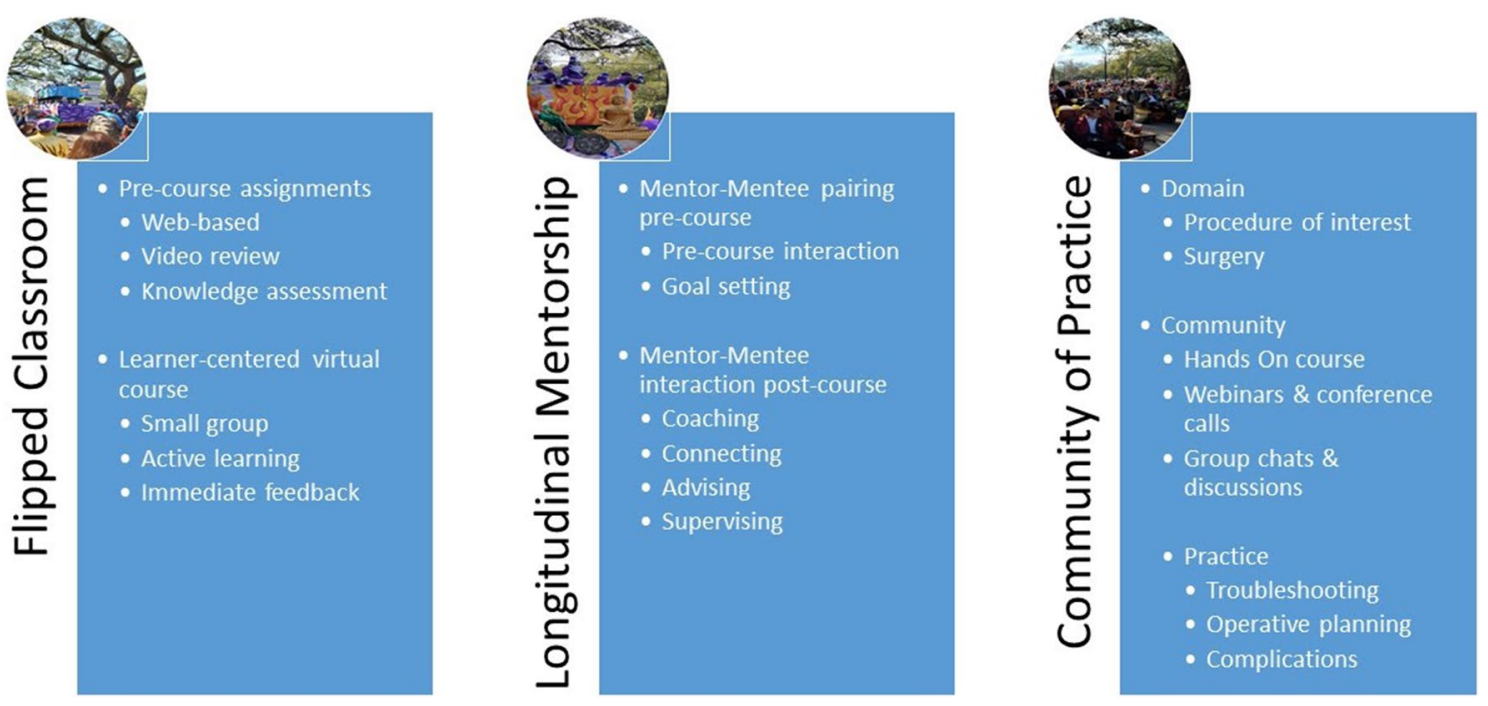

Fig. 1 Applying educational concepts to re-structure the hands-on course format 
After the virtual course itself, the mentorship relationship continues in a longitudinal fashion through interactions via calls, webinars, emails, phone conferences, and the like. Finally, the webinars, phone conferences, and group chats/ discussions create a community of practice that provides legitimate peripheral learning for the enrollees. Through this community of practice, both mentors and mentees learn tips and tricks related to overcoming challenges, treating complications, and planning for difficult operations, helping to improve practice overall.

\section{Technological requirements for REAL}

Although the concepts of flipped classroom, longitudinal mentorship, and community of practice form the foundation of the REAL educational principles and theory, its implementation is possible due to technological advances in distance learning and communication. These innovations build on traditional web-based mechanisms of teaching as well as simulation-based modalities for learning. Through such tele-collaboration using simulation-based training, REAL moves from the realm of theory to the reality of application.

\section{Tele-collaboration platforms enabling virtual interactions}

Traditionally, virtual teaching of new techniques and procedures involved asynchronous viewing of recorded videos or synchronous live-streaming of simulated or real procedures [43]. Although useful, such instruction lacked two critical components of immersive education: (1) the hands-on experience of the learner interacting physically (i.e., touching, dissecting, and manipulating) with a model and (2) the backand-forth interaction between instructor and learner while using the model. Advances in web-based communication and social interaction have made such tele-collaboration possible, enabling a more experiential learning experience that enhances learning and adoption of skills. The SAGES Project 6 Technology Working Group has outlined requirements for technology related to tele-collaboration via telementoring in a white paper that provides advice regarding minimal requirements [44].

Three main manifestations of tele-collaboration have utility during hands-on procedural training. The first form is via audiovisual interactions using existing software found in social media or distance conferencing applications [45]. This form of tele-collaboration is the easiest to implement due to its lack of complicated requirements and the ubiquity of applications on the world wide web. Its requirements include computer hardware, internet connectivity, and access to video and microphone sources. Approximately 250 such programs exist, having a wide range of subscription costs, bandwidth, and reliability [46]. Some of these services are free of charge, providing a cost-effective alternative when budgets are tight. A major drawback of audiovisual tele-collaboration arises from the fact that the teaching interaction can only occur via verbal instruction. A straightforward point can potentially become rather convoluted using only verbal teaching.

A second manifestation of tele-collaboration involves audiovisual interaction with the addition of telestration, a frequent, modality employed for surgical telementoring [47]. Available software allows for annotation or pointing on a mutually shared live video feed to enhance teaching [48]. Depending on the programming, both instructors and learners can potentially manipulate a pointer or cursor. Additionally, they can draw on a shared screen, allowing for specific direction and straightforward demonstration of maneuvers without the challenge of verbally explaining everything. The hands-on learning becomes more interactive, as instructor or learner can identify, circle, or outline specific features of anatomy. Individuals can prevent sullying equipment by using a stylus with touch screen or mouse/touchpad covered by a protective barrier. In the SAGES Project 6 Technology Working Group white paper, it is a recommended feature of any surgical telementoring set up [44].

The final manner in which tele-collaboration can promote hands-on procedural learning is through augmented reality (AR) [49]. It is the most sophisticated form of tele-collaboration, and, consequently, is more difficult to implement than the other manifestations. By definition, $\mathrm{AR}$ is an interactive experience of a real-world environment in which computer-generated information enhances the real-world objects that reside in it [50]. This computer enhancement allows for superimposition of anatomical structures or next procedural steps, enriching the learning experience.

The three forms of tele-collaboration are not mutually exclusive. Proximie (London, United Kingdom), provides a salient surgical example of this union of all three manifestations. It has a dedicated software program that allows real-time live-streaming, on-screen telestration, and the use of augmented reality devices (e.g., instruments, participant hands) that can appear on the mutually viewed screen with use of a simple web camera set-up. "Pop-up" videos, figures, or photos can superimpose on live video with varying levels of opacity. Specifically targeting surgical instruction, the telestrations include surgical instruments, and instructors can utilize an existing library of anatomic and surgical articles, photographs, and figures. The company also provides a hub for clients that stores videos on a cloud server for later viewing with or without AR. 


\section{Privacy and encryption}

The ADOPT program engages learners longitudinally through continued interaction with teachers/mentors after the initial hands-on course. Such mentorship can include review of recorded procedures or telementoring / viewing of live surgery. Many telecommunications platforms have inherent or add-on features that provide compliance through encryption, digital security, and business associate agreements to the Health Insurance Portability and Accountability Act (HIPAA) requirements related to patient privacy. Often, each program's features and conditions combine with security features of the internet provider and the proximal and distal viewing locations to enhance HIPAA compliance [51]. When addressing HIPAA related issues, technical, physical, and administrative requirements need consideration [44].

\section{Simulation-based modalities for learner practice}

The use of models for HO training courses are the cornerstone for simulated-based transfer of technical skills. Model types include whole human cadavers, ex vivo cadaveric tissue, whole live animal, ex vivo animal tissue, synthetic models, and virtual models [52] Organic tissue may provide a more positive experience for learners, although virtual or synthetic models can be equally effective in conferring knowledge and skill [53]. The use of whole or ex vivo human cadaveric specimens can be expensive and complicated to arrange for $\mathrm{HO}$ courses that are associated with national society annual meetings. Live vivarium laboratories provide a high level of fidelity for learners, but also have extensive resource requirements, including locations with Institutional Animal Care and Use Committee (IACUC) approval and anesthesia requirements [54].

A number of commercial companies have developed enclosures for ex vivo animal tissues to take advantage of the fidelity that organic tissue provides while providing a relatively cost-effective and portable method of simulating procedures or portions of procedures. Endosim ${ }^{\circledR}$ (Bolton, MA) developed plastic trainers used in conjunction with a disposable ex vivo specimen for a variety of procedural applications in surgery, gastroenterology, interventional radiology, and other fields. Gynesim ${ }^{\circledR}$ (Lexington, MA) is a non-profit surgical education company that developed a number of hybrid models with laparosopic, open, or hysteroscopic enclosures and real, USDA-approved discarded animal tissue to simulate a variety of gynecologic procedures. When shipped to learners for in-person or remote courses, all equipment are sent, including, when necessary, a laparoscopic trainer box with HD camera and monitor, laparoscopic instruments and all necessary training supplies. The company KindHeart ${ }^{\circledR}$ (Chapel Hill, NC) developed bariatric, cardiac, and colorectal models that combine a housing with an animal tissue "cassette" for simulation of procedures. Their modular cassettes of tissue can be used with some third-party simulator housings, such as those for laparoscopic and robotic training. With all of these products, shipping is performed without special accommodations and regulated bio-disposal is not required. The specimens do have to be kept refrigerated below $40^{\circ} \mathrm{F}\left(4^{\circ} \mathrm{C}\right)$ or frozen at $0^{\circ} \mathrm{F}\left(-18^{\circ} \mathrm{C}\right)$, and shelf life ranges up to 30 days refrigerated or 6 months frozen.

While purely synthetic models made from rubber or silicon may have limited application because of low-fidelity for advanced, post-graduate training of surgical procedures, when a high level of realism is applied, the learner experience can be enhanced or even superior to training on cadaveric or animal tissue [55]. The company Syndaver ${ }^{\circledR}$ (Tampa, FL) has developed high-fidelity, synthetic tissue made of water, salts, and cellulose that can recreate entire human cadavers with the potential for simulated bleeding. It has successfully developed full scale canine synthetic cadavers for use by veterinary students [56] and synthetic airway models used in the military [57]. The cost of these models can be a limiting factor as whole models can exceed 100,000 USD and partial models can range in the 10,000's USD.

\section{A REAL response to the pandemic-piloting an at-home hands-on virtual ADOPT program}

With the cancelation of 2020 Annual Meeting due to the COVID-19 pandemic, the directors of the planned ADOPT Hernia HO course had an opportunity to apply the various components of REAL to create the At-Home Hands-On Hernia ADOPT Course [58]. The course timeline was restructured to make it independent of the Annual Meeting. The directors then examined various tele-collaboration platforms for conducting the HO instruction. Due to its multiple capabilities, they settled on the Proximie Ltd virtual telementoring platform as the medium for teaching the $\mathrm{HO}$ portion of the course. Next, the directors tested various animal and synthetic models of the abdominal wall for teaching the Transversus Abdominis Release technique for repairing large defects. They chose a KindHeart porcine model that had undergone some additional prepping to highlight the various layers of the abdominal wall.

For teaching the course, a flipped classroom format allowed participants to review videos and lectures prior to the day of the virtual training in order to prepare. Additionally, a pretraining video call allowed faculty to meet with their assigned learners to establish learning objectives and to begin to develop the mentee-mentor relationship. Prior to the day of training, SAGES shipped learners the porcine model, training box, and additional equipment with instructions for setting 
it up. On the day of the virtual training, instructors used the Lapco TT standardized teaching techniques to guide each of their learners through a Transversus Abdominis Release using the porcine model on the Proximie telementoring platform.

Subsequently, mentors and mentees participated in eight distance conferencing sessions during which faculty presented specific subjects related to hernia repair. In addition, all participants discussed recent or upcoming complex hernia cases to learn new approaches and to troubleshoot challenges together. In this manner, they have acted as a community of practice helping to improve care to their patients.

The initial HO virtual training session using the augmented reality platform and enhanced porcine model was held without much technical difficulty and was very well received by participants who felt that it was successful in helping them meet their needs and learning objectives [58]. Currently, data analysis is underway related to the overall impact of the course as well as the utility of the teleconferences and mentoring.

\section{Conclusion}

Although the COVID-19 pandemic brought many challenges to continuing professional development due to the forced cancellation of national meetings and in-person HO courses, it provided an opportunity to reimagine education and learning to develop innovative, exciting alternatives to the traditional paradigm. The At-Home Hands-On Hernia ADOPT Course was the result of such reimaging. In it, standardized instruction, small group interaction, tele-collaboration, a flipped classroom format, longitudinal mentorship, and the concept of a community of practice have combined to produce a pilot program in which the latest technology in communication and the most up to date surgical models merge with the most recent best practices in education and teaching to create a new paradigm for continuing professional development for this period of social distancing and disruption.

\section{Declarations}

Disclosures Dr. Dort, Dr. Qureshi, and Dr. Tsuda have no conflicts of interest or financial ties to disclose. Dr. Paige receives grants from IAMSE, SGEA, Avista, and LIFT2, royalties from Oxford University Press and Springer Nature, and consulting fees from Boston Scientific. Ms. Schwarz is on the Editorial Board of Almanac, Alliance for CEhp, and receives consulting fees from BSC Management, LLC.

\section{References}

1. Dort J, Trickey A, Paige J, Schwarz E, Dunkin B (2019) Hands-on 2.0: improving transfer of training via the Society of American Gastrointestinal and Endoscopic Surgeons (SAGES)
Acquisition of Data for Outcomes and Procedure Transfer (ADOPT) program. Surg Endosc 33(9):3062-3068

2. Dort J, Trickey A, Paige J, Schwarz E, Cecil T, Coleman M, Dunkin B (2018) All in: expansion of the acquisition of data for outcomes and procedure transfer (ADOPT) program to an entire SAGES annual meeting hands on hernia course. Surg Endosc 32(11):4491-4497

3. Dort J, Trickey A, Schwarz E, Paige J (2019) Something for everyone: the benefits of longitudinal mentorship with the application of the acquisition of data for outcomes and procedure transfer (ADOPT) program to a SAGES hands-on colectomy course. Surg Endosc 33(9):3062-3068

4. Wyles SM, Miskovic D, Ni Z et al (2011) Analysis of laboratory-based laparoscopic colorectal surgery workshops within the English national training programme. Surg Endosc 25(5):1559-1566

5. McGaghie WC, Issenberg SB, Petrusa ER, Scalese RJ (2010) A critical review of simulation-based medical education research: 2003-2009. Med Educ 44(1):50-63

6. Cook DA, Andersen DK, Combes JR, Feldman DL, Sachdeva AK (2018) The value proposition of simulation-based education. Surgery 163(4):944-949

7. Paige JT, Farrell TM, Bergman S et al (2013) Evolution of practice gaps in gastrointestinal and endoscopic surgery: 2012 report from the Society of American Gastrointestinal and Endoscopic Surgeons (SAGES) continuing education committee. Surg Endosc 27(12):4429-4438

8. Farrell TM, Bergman S, Selim N et al (2012) Practice gaps in gastrointestinal and endoscopic surgery (2011): A report from the Society of American Gastrointestinal and Endoscopic Surgeons (SAGES) continuing education committee. Surg Endosc 26(12):3367-3381

9. Willis RE, Van Sickle KR (2015) Current status of simulationbased training in graduate medical education. Surg Clin N Am 95(4):767-779

10. Wyles SM, Schwarz E, Dort J, Tariq N, Cecil T, Coleman MG, Paige J, Dunkin BJ (2017) SAGE(S) advice: application of a standardized train the trainer model for faculty involved in a Society of American Gastrointestinal and Endoscopic Surgeons (SAGES) hands-on course. Surg Endosc 31(5):2017-2022

11. Mackenzie H, Cuming T, Miskovic D, Wyles SM, Langsford L, Anderson J, Thomas-Gibson S, Valori R, Hanna GB, Coleman MG, Francis N (2015) Design, delivery, and validation of a trainer curriculum for the national laparoscopic colorectal training program in England. Ann Surg 261(1):149-156

12. Day RW, Taylor BM, Bednarski B, Tzeng CWD, Gershenwald JE, Lee JE, Grubbs EG (2020) Virtual interviews for surgical training program applications during COVID-19: lessons learned and recommendations. Ann Surg 272(2):e144-e147. https://doi.org/ 10.1097/SLA.0000000000004064

13. McKechnie T, Levin M, Zhou K, Freedman B, Palter VN, Grantcharov TP (2020) Virtual surgical training during COVID19: operating room simulation platforms accessible from home. Ann Surg 272(2):e153-e154. https://doi.org/10.1097/SLA.00000 00000003999

14. Al-Jabir A, Kerwan A, Nicola M, Alsafi Z, Khan M, Sohrabi C, O’Neill N, Iosifidis C, Griffin M, Mathew G, Agha R (2020) Impact of the Coronavirus (COVID-19) pandemic on surgical practice-Part 2 (surgical prioritization). Int J Surg 20:233

15. Coe TM, Jogerst KM, Sell NM, Cassidy DJ, Eurboonyanun C, Gee D, Phitayakorn R, Petrusa E (2020) Practical techniques to adapt surgical resident education to the COVID-19 era. Ann Surg 272:e139

16. Rubinger L, Gazendam A, Ekhtiari S, Nucci N, Payne A, Johal H, Khanduja V, Bhandari M (2020) Maximizing virtual meetings and conferences: a review of best practices. Int Orthop 44:1461 
17. Rimmer A (2020) Covid-19: Medical conferences around the world are cancelled after US cases are linked to Massachusetts meeting. BMJ 368:m1054

18. Flipped Learning Network. The Four Pillars of F-L-I-PTM. https://flippedlearning.org/definition-of-flipped-learning/ Accessed 14 June 2020

19. Chen KS, Monrouxe L, Lu YH, Jenq CC, Chang YJ, Chang YC, Chai PYC (2018) Academic outcomes of flipped classroom learning: a meta-analysis. Med Educ 52:910-924

20. Chen F, Lui AM, Martinelli SM (2017) A systematic review of the effectiveness of flipped classrooms in medical education. Med Educ 51:585-597

21. Moffet J (2015) Twelve tips for "flipping" the classroom. Med Teach 37(4):331-336

22. Hew KF, Lo CK (2018) Flipped classroom improves student learning in health professions education: a meta-analysis. BMC Med Educ 18:38

23. Evans L, Vanden Bosch ML, Harrington S, Schoofs N, Coviak C (2019) Flipping the classroom in health care higher education: a systematic review. Nurse Educ 44:74-78

24. Chiu HY, Kang YN, Wang WL, Huang HC, Wu CC, Hsu W, Tong YS, Wei PL (2017) The effectiveness of simulation-based flipped classroom in the acquisition of laparoscopic suturing skills in medical students-a pilot study. J Surg Educ 75:326-332

25. Jones-Bonofiglio KD, Willett T, Ng S (2017) An evaluation of flipped e-learning experiences. Med Teach 40:953-961

26. Kim YJ (2016) The Odyssey and mentorship today. The Standford Daily. https://www.stanforddaily.com/2016/10/27/the-iliad-andmentorship-today/. Accessed 17 June 2020

27. Burgess A, van Diggele C, Mellis C (2018) Mentorship in the health professions: a review. Clin Teach 15:197-202

28. Krishna LKR, Renganathan Y, Tay KT, Tan BJX, Chong JY, Ching AH, Prakash K, Quek NWS, Peh RH, Chin AMC, Taylor DCM, Mason S, Kanesvaran R, Toh YP (2019) Educational roles as a continuum of mentoring's role in medicine-systematic review and thematic analysis of educational studies from 2008 to 2018. BMC Med Educ 19:439

29. Chopra V, Arora VM, Saint S (2018) Will you be my mentor? Four archtypes to help mentees succeed in academic medicine. JAMA Intern Med 178:175-176

30. El-Gabri D, McDow AD, Quamme SP, Hooper-Lane C, Greenberg CC, Long KL (2020) Surgical coaching skills for advancement of global surgical skills and capacity: a systematic review. J Surg Res 246:499-505

31. Cunningham BP, Bakker CJ, Parikh HR, Johal H, Swiontkowski MF (2019) Physician behavior change: a systematic review. J Orthop Trauma 33:S62-S72

32. Lee FQH, Chua WJ, Cheong CWS, Tay KT, Hian EKY, Chin AMC, Toh YP, Mason S, Krishna LKR (2019) A systematic scoping review of ethical issues in mentoring in surgery. J Med Educ Cur Dev 6:1-13

33. Miskovic D, Wyles SM, Ni M, Darzi AW, Hanna GB (2010) Systematic review on mentoring and simulation laparoscopic colorectal surgery. Ann Surg 252:943-951

34. Jaffer U, Vaughan-Huxley E, Standfield N, John NW (2012) Medical mentoring via the evolving world wide web. J Surg Educ 70:121-128

35. Erridge S, Yeung DKT, Patel HRH, Purkayastha S (2019) Telementoring of surgeons: a systematic review. Surg Innov 26:95-111

36. Wegner-Trayner E, Wegner-Trayner B (2015) Communities of practice a brief introduction. https://wenger-trayner.com/intro duction-to-communities-of-practice/ Accessed 17 June 2020.

37. Hoadley C (2012) What is a community of practice and how can we support it? In: Land S, Jonassen D (eds) Theoretical foundations of learning environments, 2nd edn. Routledge, Taylor \& Francis Group, New York

38. Gandamihardja T, Nestel D (2020) Communities of practice and surgical training. In: Nestel D et al (eds) Advances in surgical education-theory, evidence, practice. Springer, Singapore

39. Quinn EM, Cantillon P, Redmond HP, Bennett D (2014) Surgical journal club as a community of practice: a case study. J Surg Educ 71:606-612

40. Rolls K, Hansen M, Jackson D, Elliott D (2016) How health care professionals use social media to create virtual communities: an integrative review. J Med Internet Res 18:e166

41. Dong C, Cheema M, Samarasekera D, Rajaratnam V (2015) Using LinkedIn for continuing community of practice among hand surgeons worldwide. J Cont Educ Health Prof 35:185-191

42. McLoughlin C, Patel KD, O'Callaghan T, Reeves S (2018) The use of virtual communities of practice to improve interprofessional collaboration and education: findings from an integrative review. J Interprof Care 32:136-142

43. Rosser JC Jr, Young SM, Klonsky J (2007) Telementoring: an application whose time has come. Surg Endosc 21(8):1458-1463. https://doi.org/10.1007/s00464-007-9263-3

44. Bogen EM, Schlachta CM, Ponsky T (2019) White paper: technology for surgical telementoring-SAGES Project 6 Technology Working Group. Surg Enosc 33:684-690

45. Chick RC, Clifton GT, Peace KM, Propper BW, Hale DF, Alseidi AA, Vreeland TJ (2020) Using technology to maintain the education of residents during the COVID-19 pandemic. J Surg Educ 77(4):729-732. https://doi.org/10.1016/j.jsurg.2020.03.018

46. https://www.beckershospitalreview.com/lists/250-telehealthcompanies-to-know-2018.html

47. Erridge S, Yeung DKT, Patel HRH, Purkayastha S (2019) Telementoring of surgeons: a systematic review. Surg Innov 26(1):95111. https://doi.org/10.1177/1553350618813250

48. Tsuda S, Olasky J, Jones DB (2021) Team training and surgical crisis management. J Surg Oncol 124(2):216-220. https://doi.org/ $10.1002 /$ jso. 26523

49. Rojas-Muñoz E, Cabrera ME, Andersen D, Popescu V, Marley S, Mullis B, Zarzaur B, Wachs J (2019) Surgical telementoring without encumbrance: a comparative study of see-through augmented reality-based approaches. Ann Surg 270(2):384-389. https://doi. org/10.1097/SLA.0000000000002764

50. Tsuda ST, Scott DJ, Jones DB (2012) Textbook of simulation: skills \& team training. Ciné-Med Pub, Woodbury

51. Bogen EM, Schlachta CM, Ponsky T (2019) White paper: technology for surgical telementoring-SAGES Project 6 Technology Working Group. Surg Endosc 33(3):684-690. https://doi.org/10. 1007/s00464-018-06631-8

52. Tsuda S, Scott D, Doyle J, Jones DB (2009) Surgical skills training and simulation. Curr Probl Surg 46(4):271-370. https://doi.org/ 10.1067/j.cpsurg.2008.12.003

53. Lombardi SA, Hicks RE, Thompson KV, Marbach-Ad G (2014) Are all hands-on activities equally effective? Effect of using plastic models, organ dissections, and virtual dissections on student learning and perceptions. Adv Physiol Educ 38(1):80-86. https:// doi.org/10.1152/advan.00154.2012 (PMID: 24585474)

54. Ali J, Sorvari A, Pandya A (2012) Teaching emergency surgical skills for trauma resuscitation-mechanical simulator versus animal model. Int Sch Res Not. https://doi.org/10.5402/2012/259864

55. Bohl MA, McBryan S, Spear C, Pais D, Preul MC, Wilhelmi B, Yeskel A, Turner JD, Kakarla UK, Nakaji P (2019) Evaluation of a novel surgical skills training course: are cadavers still the gold standard for surgical skills training? World Neurosurg 127:63-71. https://doi.org/10.1016/j.wneu.2019.03.230

56. Yong JAA, Kim SE, Case JB (2019) Survey of clinician and student impressions of a synthetic canine model for gastrointestinal 
surgery training. Vet Surg 48(3):343-351. https://doi.org/10.1111/ vsu. 13144

57. Schauer SG, Fernandez JRD, Roper JL, Brown D, Jeffers KL, Srichandra J, Davids NB, April MD (2018) A randomized crossover study comparing surgical cricothyrotomy techniques by combat medics using a synthetic cadaver model. Am J Emerg Med 36(4):651-656. https://doi.org/10.1016/j.ajem.2017.11.062

58. Greenberg JA, Schwarz E, Paige J, Dort J, Bachman S (2021) At-home hands-on surgical training during COVID19: proof of concept using a virtual telementoring platform. Surg Endosc 35(5):1963-1969. https://doi.org/10.1007/s00464-021-08470-6

Publisher's Note Springer Nature remains neutral with regard to jurisdictional claims in published maps and institutional affiliations. 